\title{
AVALIAÇÃO DO CRESCIMENTO DE BACTÉRIAS LÁCTICAS EM SALSICHAS RECOBERTAS COM FILME COMESTÍVEL CONTENDO NANOPARTÍCULAS DE PRATA
}

\author{
K. C. KAUFMANN ${ }^{1}$, I. J. MANSO ${ }^{1}$, O. H. GONÇALVES ${ }^{2}$, M. A. SHIRAI ${ }^{2}$, L. BRACHT ${ }^{1}$, \\ F. V. LEIMANN² \\ ${ }^{1}$ Universidade Tecnológica Federal do Paraná, Departamento Acadêmico de Alimentos; \\ ${ }^{2}$ Universidade Tecnológica Federal do Paraná, Programa de Pós-Gradução em Tecnologia de \\ Alimentos \\ E-mail para contato: fernandaleimann@utfpr.edu.br
}

\begin{abstract}
RESUMO - Filmes comestíveis atuam como uma barreira a fatores como microrganismos, umidade, óleos, gases e vapores prolongando a vida útil e qualidade dos alimentos. No presente trabalho filmes comestíveis de amido contendo nanopartículas de prata (AgNPs) foram aplicados a salsichas e a ação antimicrobiana das mesmas foi avaliada. As amostras de salsichas contendo AgNPs tiveram sua carga microbiana significativamente reduzida $(p 0,05)$ quando comparadas as amostras do controle (sem o filme comestível). As amostras foram avaliadas durante um intervalo de tempo de 0,15 e 30 dias.
\end{abstract}

\section{INTRODUÇÃO}

A aplicação dos filmes comestíveis a carnes, aves, peixes frescos, frutas e verduras tem tido crescente interesse, pois proporciona o aumento do tempo de prateleira e qualidade dos produtos (Du et al., 2011). De acordo com Vásconez et al. (2009) há possibilidade de incorporar nos filmes comestíveis diferentes aditivos, tais como antimicrobianos, antioxidantes, nutracêuticos e agentes aromatizantes. Em particular, a utilização de filmes comestíveis contendo ativos antimicrobianos tem mostrado ser uma ferramenta útil para proteção dos alimentos contra deterioração e para diminuição do risco de crescimento de patógenos. Diversos estudos têm demonstrado que filmes com propriedades antimicrobianas podem reduzir os níveis bacterianos em produtos cárneos (Cagri et al., 2002). A prata metálica na forma de nanopartículas vem sendo aplicada a filmes comestíveis visando a inibição do crescimento de microrganismos em alimentos como cogumelos tipo shitake (Jiang et al., 2013), cenouras minimamente processadas (Costa et al., 2012) e aspargos (An et al., 2008). Dessa forma torna-se interessante a aplicação das nanopartículas de prata aos produtos cárneos como as salsichas, que podem apresentar alterações causados por microrganismos em condições de aerobiose podemos citar como a limosidade superficial (de Alcantara et al., 2012).

O objetivo do presente trabalho é sintetizar nanopartículas de prata (AgNPs) através de técnica de baixo impacto ambiental (síntese verde) e aplicá-las na forma de filmes comestíveis em salsichas para avaliação da sua efetividade contra o crescimento de microorganismos. 


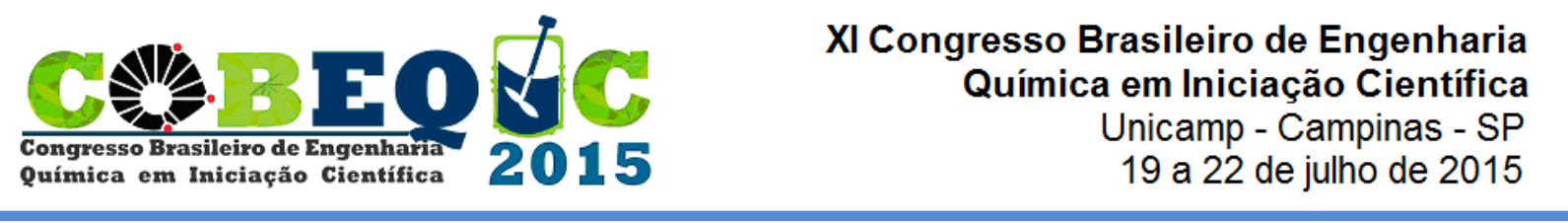

\section{MATERIAIS E MÉTODOS}

\subsection{Materiais}

Amido solúvel (Merk), D-glicose (Isofar) e nitrato de prata (Proquímios) foram utilizados na síntese das nanopartículas de prata. Ágar MRS (Biomak) e solução salina foram utilizados nas análises microbiológicas. As salsichas foram adquiridas em um mercado local, na cidade de Campo Mourão-PR, em pacote de $2 \mathrm{~kg}$.

\subsection{Síntese das AgNPs}

As nanopartículas foram preparadas pela técnica do polissacarídeo modificada (Ghaseminezhad et al., 2012). Na Figura 1 está representado um esquema representativo da síntese. Soluções aquosas de nitrato de prata $(2 \mathrm{~mL}, 25 \mathrm{mM})$, de amido (gelatinizado a $90{ }^{\circ} \mathrm{C}$, $50 \mathrm{~mL}, 1 \% \mathrm{~g} / \mathrm{g})$ e de D-glicose $(4 \mathrm{~mL}, 25 \mathrm{mM})$ foram preparadas. Em seguida as soluções foram homogeneizadas com agitação magnética por $5 \mathrm{~min}$. Finalmente a solução resultante foi autoclavada a $121^{\circ} \mathrm{C}$ e $15 \mathrm{psi}$ (Prismatec) por $15 \mathrm{~min}$. Ao final do procedimento a solução apresentou coloração amarelo marrom, indicando a formação das AgNPs. A solução foi armazenada a temperatura ambiente.

Figura 1 - Esquema representativo da síntese das AgNPs

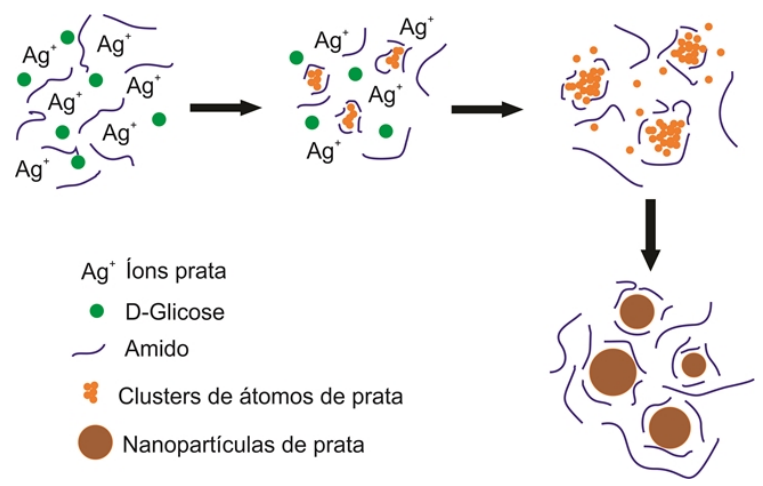

\subsection{Aplicação do filme comestível contendo as AgNPs}

Todos os materiais e utensílios utilizados no procedimento foram previamente esterilizados em autoclave (Prismatec). A solução de amido contendo as AgNPs (resultante da síntese) foi aplicada no recobrimento das salsichas. A concentração de AgNPs para aplicação foi mantida em $37,5 \mu \mathrm{g} / \mathrm{mL}$ de acordo com o resultado obtido na análise de CIM para o microrganismo de maior resistência (Staphylococus aureus) anteriormente por Manso et al. (2014). Para isso a solução de síntese foi diluída em água destilada estéril. As salsichas foram mergulhadas, durante 1 minuto, na solução. Para cada intervalo de tempo de avaliação $(0,15$ e 30 dias), 3 salsichas foram recobertas com a solução de AgNPs e embaladas a vácuo (Sulpack) em duplicata. O mesmo método foi realizado para as salsichas sem o recobrimento com filme comestível (controle). Todas as amostras embaladas a vácuo (controle e tratamento com AgNPs), foram armazenadas na geladeira a $10{ }^{\circ} \mathrm{C}$. 


\subsection{Contagem total de bactérias lácticas}

Foi determinada a quantidade de bactérias presente na superfície das salsichas, para tanto porções de $25 \mathrm{~g}$ de salsicha foram pesadas assepticamente e homogeneizadas com 225 $\mathrm{mL}$ de solução salina, durante 60 segundos, em um stomacher (ITR, MR1204). A partir desta diluição $\left(10^{-1}\right)$, foram realizadas diluições decimais seriadas $\left(10^{-2}\right.$ e $\left.10^{-3}\right)$. Posteriormente amostras de $1 \mathrm{~mL}$ de cada diluição foram plaqueadas, em triplicata, por meio da técnica de semeadura em profundidade em ágar MRS (seletivo para bactérias ácido lácticas). $\mathrm{O}$ procedimento foi realizado sob um fluxo laminar (Veco). As placas foram incubadas a $37{ }^{\circ} \mathrm{C}$, por 48 horas em estufa para cultura bacteriológica (Quimis). Após incubação, as colônias características da espécie foram contadas (Phoenix). Os resultados foram submetidos ao Teste-t a um nível de significância de 5\% utilizando o software Statistica 7.0

\section{RESULTADOS}

$\mathrm{Na}$ Tabela 1 estão apresentados os resultados das médias finais obtidas nas contagens das colônias das bactérias ácido lácticas (BAL) que cresceram nas placas contendo meio de cultura tanto para o grupo de controle quanto para o grupo tratado com as AgNPs. O teste-t, foi aplicado separadamente para cada dia, para verificar se houve diferença estatística entre as médias do crescimento bacteriano das salsichas recobertas com AgNPs e das salsichas controle, sendo os resultados apresentados na Tabela 2 a um nível de significância de 5\%.

Tabela 1 - Contagem das colônias de bactérias nas placas de ágar para cada intervalo de tempo: controle e filme comestível contendo AgNPs

\begin{tabular}{ccccc}
\hline \multirow{2}{*}{ Tempo (dias) } & \multicolumn{2}{c}{ Controle } & \multicolumn{2}{c}{ Filme comestível AgNPs } \\
\cline { 2 - 5 } & Diluição & UFC/25g & Diluição & UFC/25g \\
\hline 0 & $10^{-1}$ & $3,33 \times 10^{1}$ & $10^{-1}$ & $1,5 \times 10^{1}$ \\
15 & $10^{-1}$ & $3,85 \times 10^{1}$ & $10^{-1}$ & $<10$ \\
30 & $10^{-3}$ & $19,53 \times 10^{4}$ & $10^{-1}$ & $1,275 \times 10^{3}$ \\
\hline
\end{tabular}

Tabela 2 - Análise estatística (teste-t) aplicado à contagem de colônias das amostras de salsicha: controle e filme comestível contendo AgNPs $(\alpha=5 \%)$

\begin{tabular}{cccccc}
\hline $\begin{array}{c}\text { Tempo } \\
\text { (dias) }\end{array}$ & $\begin{array}{c}\text { Média AgNPs } \\
(\mathrm{UFC} / 25 \mathrm{~g})\end{array}$ & $\begin{array}{c}\text { Média controle } \\
(\mathrm{UFC} / 25 \mathrm{~g})\end{array}$ & t-valor & $\begin{array}{c}\text { Graus de } \\
\text { liberdade }\end{array}$ & $\mathrm{p}$ \\
\hline 0 & 5,00 & 33,30 & $-3,20$ & 4 & 0,032505 \\
15 & 0,00 & 385,00 & $-5,11$ & 4 & 0,006895 \\
30 & $1.275,00$ & $195.333,3$ & $-14,95$ & 4 & 0,000117 \\
\hline
\end{tabular}

É possível observar que em todos os dias analisados o crescimento de bactérias foi significativamente maior nas salsichas que não foram recobertas com a solução contento AgNPs (controle). O teste-t mostrou que, para todos os intervalos de tempo em que foram realizadas as análises, as duas médias diferem significativamente entre si ao nível de $95 \%$ de confiança, pois o valor de $\mathrm{p}$ foi menor que $5 \%$ para todos os testes. 
$\mathrm{Na}$ contagem de colônias para as amostras preparadas no primeiro dia (0 dias) houve crescimento de bactérias nas placas tanto para as salsichas contendo AgNPs quanto para o controle. As nanopartículas de prata causaram redução significativa de bactérias mesmo em pouco tempo de contato, o que indica uma rápida atividade antimicrobiana das nanopartículas de prata. Além disso as amostras que permaneceram armazenadas na geladeira, após 15 dias não apresentaram crescimento bacteriano significativo $(<10 \mathrm{UFC} / 25 \mathrm{~g})$ em nenhuma placa das amostras de salsichas que foram recobertas com filme contendo AgNPs.

As salsichas analisadas após 30 dias (ainda dentro do prazo de validade do produto) apresentaram alto crescimento microbiano. Apesar de haver ocorrido crescimento nas salsichas tratadas com AgNPs esse crescimento ainda apresentou diferença significativa com relação ao controle. No caso do controle, além das placas apresentarem maior número de colônias de bactérias, as contagens foram realizadas nas placas com diluição $10^{-3}$, pois nas diluições menores pelo alto índice de crescimento, não foi possível fazer a leitura.

Como não houve crescimento significativo de bactérias nas salsichas recobertas com AgNPs após 15 dias de armazenamento é possível afirmar que as AgNPs mantiveram a segurança das mesmas por um período 15 dias maior que as salsichas sem tratamento. An et al. (2008) reportaram que AgNPs em um revestimento de PVP aplicado a aspargos impediram significativamente o crescimento de microrganismos, aumentando sua vida de prateleira em 10 dias quando armazenados sob refrigeração $\left(2^{\circ} \mathrm{C}\right.$ a $\left.10^{\circ} \mathrm{C}\right)$.

\section{CONCLUSÃO}

A eficiência antimicrobiana das nanopartículas de prata foi confirmada pelas análises microbiológicas. As salsichas armazenadas na geladeira contendo o filme com nanopartículas de prata tiveram crescimento de bactérias significativamente inferior as salsichas do controle, sendo que as amostras de salsichas revestidas com as AgNPs, avaliadas após 15 dias de armazenamento, não apresentaram crescimento microbiano significativo

\section{AGRADECIMENTOS}

Os autores agradecem à Fundação Araucária e ao CNPq/PIBIT.

\section{REFERÊNCIAS}

AN, J.; ZHANG, M.; WANG, S.; TANG, J. Physical, chemical and microbiological changes in stored green asparagus spears as affected by coating of silve nanoparticles- PVP. $L W T$, v. 41, p. 1100-1107, 2008.

CAGRI, A.; USTUNOL, Z.; RYSER, E. T. Inhibition of three pathogens on bologna and summer sausage using antimicrobial edible films. J. Food Sci., v. 67, p. 2317-2324, 2002.

COSTA, C.; CONTE, A.; BUONOCORE, G. G.; LAVORGNA, M.; DEL NOBILE, M. A. Calcium-alginate coating loaded with silver-montmorillonite nanoparticles to prolong the shelf-life of fresh-cut carrots. Food Res. Int., v. 48, p. 164-169, 2012. 


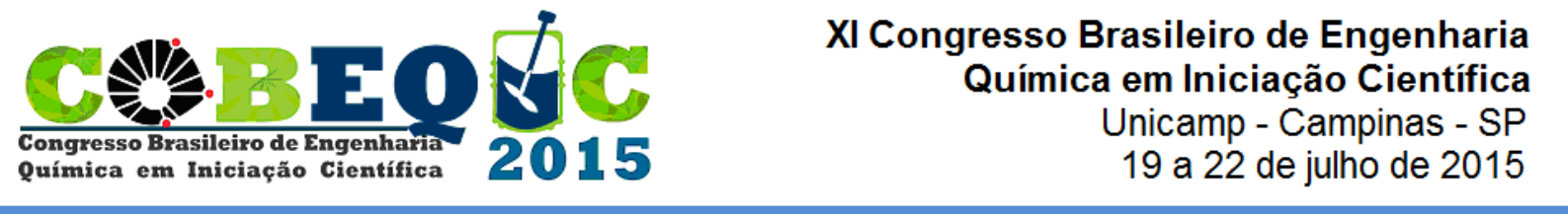

DE ALCANTARA, M.; DE MORAIS, I. C. L.; DE MATOS, C.; DE SOUZA, O. D. C. C. Principais Microrganismos envolvidos na deterioração das características sensoriais de derivados cárneos. Ver. Bras. Hig. San. Anim., v. 6, p. 1-20, 2012.

DU, W. X.; OLSEN, C. W.; AVENA-BUSTILlOS, R. J.; FRIEDMAN, M.; MCHUGH, T. H. Physical and antibacterial properties of edible films formulated with apple skin polyphenols. J. Food Sci., v. 76, p. 149-155, 2011.

GHASEMINEZHAD, S. M.; HAMEDI, S.; SHOJAOSADATI, S. A. Green synthesis of silver nanoparticles by a novel method: comparative study of their properties. Carboh. Pol., v. 89, p. 467-472, 2012.

JIANG, T.; LIFANG F.; YANBO W. Effect of alginate/nano-Ag coating on microbial and physicochemical characteristics of shiitake mushroom (Lentinus edodes) during cold storage. Food Chem.; v. 141, p. 954-960, 2013.

MANSO, I. J.; PIZOLLI, A. P. DE O.; SHIRAI, M. A; BRACHT, L.; LEIMANN, F. V. Síntese e atividade antimicrobiana de nanopartículas de prata. XXIV Congresso Brasileiro de Ciência e Tecnologia de Alimentos, 2014, Aracajú. Anais do XXIV CBCTA, 2014.

VÁSCONEZ, M. B.; FLORES, S. K.; CAMPOS, C. A.; ALVARADO, J.; GERSCHENSON, L. N. Antimicrobial activity and physical properties of chitosan-tapioca starch based edible films and coatings. Food Res. Int, v. 42, p. 762-769, 2009. 